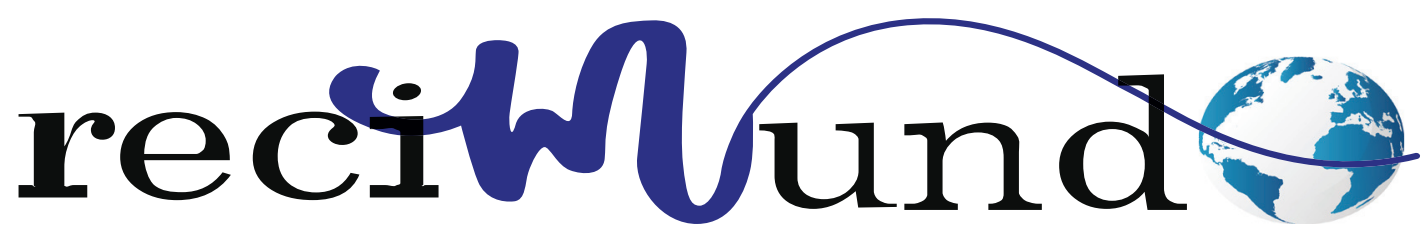

Revista Científica Mundo de la Investigación y el Conocimiento

DOI: 10.26820/recimundo/4.(4).octubre.2020.411-433

URL: http://recimundo.com/index.php/es/article/view/946

EDITORIAL: Saberes del Conocimiento

REVISTA: RECIMUNDO

ISSN: 2588-073X

TIPO DE INVESTIGACIÓN: Artículo de Revisión CÓDIGO UNESCO: 5312.02 Servicios Comunitarios, Sociales e Individuales



PAGINAS: 411-433

\title{
Evaluación social de las competencias de gestión de riesgos de un municipio en Ecuador
}

Social evaluation of risk management competencies of a municipality in Ecuador

Avaliação social das competências de gestão de risco de um município do Equador

Liliana Elizabeth Soriano Torres 1; Rodolfo Enrique Robles Salguero;

RECIBIDO: 10/07/2020 ACEPTADO: 26/08/2020 PUBLICADO: 15/10/2020

1. Licenciada en Turismo de la Escuela Superior Politecnica del Litoral; Mag'íster en Administración Pública mención Desarrollo Institucional de la Universidad Estatal de Milagro, Milagro, Ecuador; liliana.e.soriano@gmail.com; (iD https://orcid. org/0000-0002-7315-4217

2. Diploma Superior en Investigación Educativa; Diploma Superior de Cuarto Nivel en Gerencia Estratégica en Desempeño Empresarial; Diploma Superior de Cuarto Nivel en Gerencia Estratégica de Mercadeo; Magister en Administración de Empresas; Diploma Superior en Diseño para Educación Continua; Economista; Universidad Estatal de Milagro, Milagro, Ecuador; rrobless1964@gmail.com; (D) https://orcid.org/0000-0003-1016-4079

\section{CORRESPONDENCIA}

Liliana Elizabeth Soriano Torres

liliana.e.soriano@gmail.com

Milagro, Ecuador

๑ RECIMUNDO; Editorial Saberes del Conocimiento, 2020 


\section{RESUMEN}

La gestión de riesgo es un proceso para minimizar los efectos negativos, en un territorio y su población vulnerable, frente a los desastres que se puedan originar de forma natural o por actividad humana, como lo puede evidenciar en la cronología existente sobre la ocurrencia de las amenazas. Los gobiernos cantonales tienen la obligación de conformar las Unidades de Gestión de Riesgos dentro de su estructura orgánica, como lo establece la normativa vigente en Ecuador. Esta investigación estuvo centrada en uno de los cantones con clasificación D, con un presupuesto bajo por parte del Estado. La aplicación de los requerimientos base -talento humano, tecnológico, productos y servicios-, en la conformación de esta unidad, en el cantón Salinas de la provincia de Santa Elena. El análisis descriptivo se realizó bajo la modalidad documental, para evaluar las acciones preventivas, frente a los riesgos, de la población, según los productos y servicios del ámbito reducción de riesgos, como lo norma el ente rector, Servicio Nacional de Gestión de Riesgos y Emergencias, en el período 2018 a junio 2020. Permite visibilizar las gestiones autónomas que se pueden coordinar dentro del Sistema Nacional Descentralizado de Gestión de Riesgos. El financiamiento y el acompañamiento técnico especializado dentro de un proyecto social por medio de cooperación internacional pueden influir de manera positiva en el desarrollo y fortalecimiento de las capacidades de reacción de una población frente a los desastres. Los resultados obtenidos en prevención de riesgos con la comunidad y los turistas, del cantón Salinas es por la asesoría, acompañamiento de la Agencia de Cooperación Internacional de Japón, que luego del sismo ocurrido en el 2016, están ejecutando el Proyecto para la Construcción de Ciudades Seguras y Resilientes frente a Terremotos y Tsunami, en donde se encuentra otros Municipios como Portoviejo, Atacames, Esmeraldas, entre otros. A diferencia de este apoyo técnico y de financiamiento, ¿qué oportunidades tienen los otros municipios (Clasificación D) que se encuentran en la parte continental?.

Palabras clave: Gestión de riesgos, Reducción de Riesgos, Municipios, Desastres, Administración pública.

\section{ABSTRACT}

Risk management is a process to minimize the negative effects, on a territory and its vulnerable population, in the face of disasters that may originate naturally or by human activity, as can be seen in the existing chronology of the occurrence of the threats. The cantonal governments have the obligation to form Risk Management Units within their organic structure, as established by current regulations in Ecuador. This research was focused on one of the cantons with a D classification, with a low budget from the State. The application of the basic requirements -human talent, technology, products and services-, in the conformation of this unit, in the Salinas canton of the Santa Elena province. The descriptive analysis was carried out under the documentary modality, to evaluate the preventive actions, against the risks, of the population, according to the products and services of the risk reduction field, as established by the governing body, the National Risk Management Service and Emergencies, in the period 2018 to June 2020. It makes it possible to make visible the autonomous procedures that can be coordinated within the Decentralized National Risk Management System. Financing and specialized technical support within a social project through international cooperation can positively influence the development and strengthening of the reaction capacities of a population. The results obtained in risk prevention with the community and tourists, from the Salinas canton, are due to the advice, accompaniment of the Japan International Cooperation Agency, which after the earthquake that occurred in 2016, is executing the Project for the Construction of Cities Safe and Resilient against Earthquakes and Tsunami, where there are other Municipalities such as Portoviejo, Atacames, Esmeraldas, among others. In contrast to this technical and financing support, what opportunities do the other municipalities (Classification D) that are in the continental part have?

Keywords: Risk management, Risk reduction, Municipality, Disaster, Public administration.

\section{RESUMO}

A gestão de riscos é um processo de minimização dos efeitos negativos, no território e na sua população vulnerável, face a calamidades que podem ter origem natural ou pela actividade humana, conforme se pode verificar na cronologia existente de ocorrência das ameaças. Os governos cantonais têm a obrigação de constituir Unidades de Gestão de Riscos dentro de sua estrutura orgânica, conforme estabelece a normativa vigente no Equador. Esta pesquisa teve como foco um dos cantões com classificação D, com baixo orçamento do Estado. A aplicação dos requisitos básicos - talento humano, tecnologia, produtos e serviços -, na conformação desta unidade, no cantão Salinas da província de Santa Elena. A análise descritiva foi realizada na modalidade documental, para avaliar as ações preventivas, face aos riscos, da população, de acordo com os produtos e serviços da área da redução de riscos, conforme estabelecido pelo órgão de governo, o Serviço Nacional de Gestão de Riscos e Emergências, no período de 2018 a junho de 2020. Permite tornar visíveis os procedimentos autónomos que podem ser coordenados no âmbito do Sistema Nacional de Gestão de Riscos Descentralizado. O financiamento e o apoio técnico especializado dentro de um projeto social por meio da cooperação internacional podem influenciar positivamente o desenvolvimento e o fortalecimento das capacidades de reação de uma população. Os resultados obtidos na prevenção de riscos com a comunidade e turistas, do cantão de Salinas, devem-se à assessoria, acompanhamento da Agência de Cooperação Internacional do Japão, que após o terremoto ocorrido em 2016, está executando o Projeto para a Construção de Cidades Seguras e Resiliente contra Terremotos e Tsunami, onde existem outros Municípios como Portoviejo, Atacames, Esmeraldas, entre outros. Em contraste com este apoio técnico e financeiro, que oportunidades têm os outros municípios (Classificação D) que se encontram na parte continental?

Palavras-chave: Gestão de risco, Redução de risco, Município, Desastre, Administração pública. 


\section{Introducción}

En nuestro planeta ocurren con cierta frecuencia los fenómenos naturales según el territorio, pero ¿qué sucede cuando dentro de un territorio se incrementa la zona urbana o rural y la población se incrementa?, los fenómenos naturales tienen una frecuencia según los registros históricos que llevan las instituciones que la investigan.

Cuando ocurre un fenómeno natural en una zona urbana o rural, se convierte un desastre. Aquí se cumple uno de los competentes para que exista riesgo, la vulnerabilidad. Se entiende que cuando existe una exposición de uno o varios elementos a un fenómeno, entonces existe la probabilidad de que existan daños materiales o al ambiente y pérdidas de vidas humanas.

\section{Antecedentes de la Gestión de Riesgos}

En los años 70, en la zona de California en Estados Unidos, por causa de los grandes incendios forestales hubo daños materiales dando pérdidas económicas y humanas, otras personas salieron con lesiones o heridas. Por esto se realizó un estudió con el registro histórico de este tipo de eventos, descubriendo que este problema era por el inadecuado manejo de los recursos o por fallas en las tácticas (USAID, 2012).

Buscando el origen, se recurre a la historia sobre desastres y emergencias, actualmente se vive en una sociedad de riesgos, donde algunos son globales, afectando a toda la población vulnerable. Por ese motivo, el conocimiento de los riesgos de desastres se centra cada vez más en la conciencia de la generación de nuevos riesgos, además de las fallas humanas.

Los riesgos de desastres se pueden encontrar en las interdependencias entre economía, sociedad, ambiente y desarrollo tecnológico. Manejar el riesgo de desastres exige diferentes perspectivas y soluciones integrales y multidisciplinarias. Una perspectiva de seguridad social, desarrollo sostenible y territorio seguro puede aportar un contexto más amplio a soluciones que brinden resiliencia al territorio y a la sociedad. Narváez (como se citó en el Servicio Nacional de Gestión de Riesgos y Emergencias, 2019) menciona que, en el siglo pasado la Gestión del Riesgo de Desastres aparece a mediados de la década de 1990, desde esta época se reestructura la Gestión y Administración de Desastres, a diferencia del manejo que se venía ejecutando a partir de los años sesenta. Con respecto a esto se define como un proceso de construcción y desarrollo social con la finalidad de reducir riesgos, preparar a la sociedad frente a los desastres y la gestión para recuperación pos-desastres, buscando lograr frente a las amenazas existentes en el territorio, el equilibrio del manejo permanente de las capacidades y vulnerabilidades para minimizar las pérdidas humanas, económicas, ambientales dentro del desarrollo sustentable y sostenible para el territorio (Servicio Nacional de Gestión de Riesgos y Emergencias, 2019).

La autora Gellert-de Pinto (2012) en su estudio expresa que desde 1990 existe un cambio de percepción y abordaje a nivel internacional especialmente en América Latina, sobre los desastres en su gestión. Se enfoca en la posibilidad de daños y pérdidas (riesgos) que predispone la devastación (natural o antrópico), siendo que es construido socialmente (antrópico); y no solo es la ocurrencia de los desastres sino la dimensión de sus impactos negativos (riesgos). El riesgo se ha vuelto un elemento relevante para comprender ¿Cómo se construye los desastres?, para determinar los procesos, para evitar la ocurrencia de los desastres o reducir sus efectos negativos. Se encontró una gran relación entre el desarrollo territorial y el riesgo de desastre en las zonas urbanas, en donde el riesgo se genera por los procesos sociales, los modelos de desarrollo de cada sociedad. En los países de

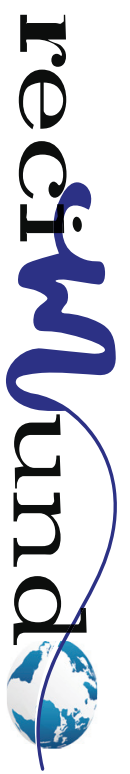


América Latina favorecen a la construcción constante de riesgos de desastres, por su deficiente gestión frente a los problemas en el desarrollo territorial.

Para minimizar los perjuicios ocurridos por las catástrofes naturales (sismos, sequías, inundaciones, entre otros), según la Oficina de las Naciones Unidas para la Reducción del Riesgo de Desastres (2018) se busca reducir a través de una cultura de prevención ante los riesgos. Los desastres son la causa de una amenaza natural o antrópica. La magnitud de las secuelas depende de las resoluciones que se adoptan, relacionadas con la forma en que se producen los alimentos, ¿dónde y cómo se construyen las viviendas, qué tipo de gobierno se tiene, cómo funciona el sistema financiero y hasta lo que se imparte en las escuelas. Cada decisión que se toma puede hacer a una población más vulnerable a los desastres.

De acuerdo a la SGR et. al (2012), afirma que en:

Ecuador los desastres que generan mayor impacto están relacionados con fenómenos hidrometerológicos (sequías e inundaciones generadas por precipitaciones estacionales, Fenómeno El Niño y penetraciones marinas), sismos, erupciones volcánicas y movimientos en masas, además de los eventos por epidemias o por tecnología; los accidentes de tránsito de los considera debido la morbilidad y mortalidad alta, que corresponde a la salud pública. (pág. 61)

Según el análisis que realiza SGR/ECHO/ UNISDR (2012) en referencia a los fenómenos hidrometerológicos, por medio de la base de datos de Desinventar de 1970 al 2010, dieron como resultado que la mayor cantidad de pérdidas se dan en la región Costa, debido al elevado nivel de concentración poblacional. Considerando un total de 6.260 registros de pérdidas de desastres, generando el desglose por tipo de evento se observa de por inundación se registraron 1.407, por deslizamiento $1.050 \mathrm{y}$ por incendio 985; siendo los tres tipos de eventos con mayor registro en ese período (Corporación OSSO-Colombia, 2010). Actualmente la base de datos aún está en función para consulta.

\section{Marco conceptual}

En primer lugar, la gestión del riesgo podría definirse como una serie de procedimientos para la identificación, el análisis y cuantificar las probabilidades de daños y pérdidas, además de los efectos que se segregan de los desastres, también como todas las acciones para la prevención, corrección y reducción que corresponden a la gestión (Keipi, Mora Castro, \& Bastidas, 2005).

Por otro lado, se encontró que el término Gestión del riesgo de desastres se considera un proceso ordenado en donde se usa lineamientos administrativos, organizacional, aptitudes y capacidades de operaciones para construir y ejecutar política, además de fortalecer y desarrollar las capacidades para afrontar y disminuir el impacto de las amenazas y la contingencia que ocurra un desastre (EIRD-Naciones Unidas, 2009). Se considera una ampliación al término "gestión de riesgos" para especificar el riesgo de desastres. Tiene la finalidad de evitar, minimizar los efectos negativos frente a eventos peligrosos por amenazas por medio de varias acciones para prevenir, mitigar y preparar (EIRD-Naciones Unidas, 2009).

Dentro de la literatura se encontró que el riego tiene una ecuación en donde se considera a la amenaza (permanente), la vulnerabilidad (variable) y la capacidad (variable); en donde estos dos últimos son claves para gestionar los riesgos frente a un desastre (Secretaría Nacional de Gestión de Riesgos, 2010). 

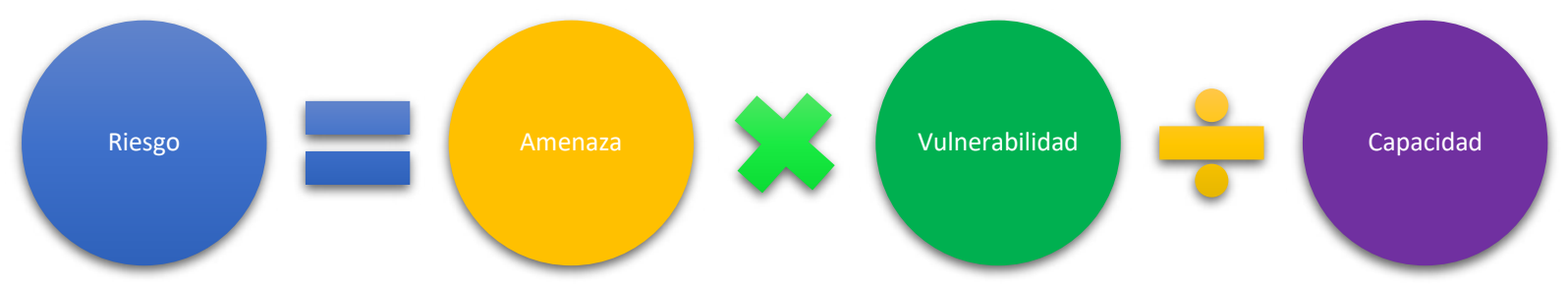

Figura I. Ecuación del riesgo: Amenaza por Vulnerabilidad sobre la Capacidad. Reducir las vulnerabilidades existentes en el territorio y fortaleciendo las capacidades, ayuda a minimizar las probabilidades de pérdidas y daños.

Fuente: DIPECHO/BID/CIIFEN/PNUD/INAMHI, 2008

Elaboración: Soriano, Liliana

El ente rector a nivel nacional, maneja las definiciones de los siguientes términos comunes en este ámbito:

\section{Riesgos de desastres}

Es la probabilidad de pérdidas de vidas humanas o daños ocurridos en el territorio en un tiempo específico, determinado por la presencia de amenazas, vulnerabilidades y capacidades de respuesta al impacto (Secretaría de Gestión de Riesgos, 2018, pág. 13).

\section{Amenazas}

En el sentido más general, las amenazas se refieren a fenómenos o actividades humanas que pueden ocasionar disrupciones sociales, económicas o daños al ambiente, fallecidos, heridas u otros efectos en la salud de la población (Secretaría de Gestión de Riesgos, 2018).

\section{Vulnerabilidad}

Factores físicos, económicos, ambientales y sociales que determinan el aumento de la susceptibilidad en los bienes, persona, comunidad o en los sistemas, como consecuencia de las amenazas (Secretaría de Gestión de Riesgos, 2018).

\section{Capacidad}

Conjunto de recursos, atributos y fortalezas disponibles en un territorio, comunidad o sociedad, que se puedan usar para la gestión y la reducción de los riesgos de desastres y afianzar la resiliencia (Secretaría de Gestión de Riesgos, 2018).

Los principios más comunes que se usan para las actividades en gestión de riesgos en los municipios para su gestión y articulaciones son los siguientes:

\section{Igualdad}

Ninguna persona puede ser segregada por razones de condición migratoria, orientación sexual, discapacidad, estado de salud, condición socioeconómica, pasado judicial, estado civil, filiación política, identidad cultural, etnia, religión, identidad de género, edad, sexo, y lugar de nacimiento porque todos gozarán de los mismos derechos, oportunidades y protección ante una emergencia o desastre, porque todos somos iguales (Secretaría de Gestión de Riesgos, 2018).

\section{Transparencia}

De manera oportuna y veraz se deberá comunicar a la población toda la información respectiva a emergencias y desastres de-

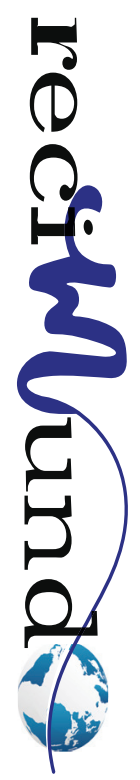


berá ser comunicada a la ciudadanía, a través de los canales oficiales (Secretaría de Gestión de Riesgos, 2018).

\section{Transversalidad}

La gestión de riesgos debe ser incorporada de manera obligatoria y transversal en todas las entidades públicas y privadas en sus operaciones y planificación (Secretaría de Gestión de Riesgos, 2018).

\section{Descentralización Subsidiaria}

Las acciones de la Gestión de Riesgos se deberán ejecutar sin relevar de su responsabilidad a la entidad local o regional, únicamente cuando su capacidad de gestión sea limitada, las entidades de mayor ámbito a nivel territorial y con más capacidad financiera y técnica la asumirá proyectando la ejecución bajo este principio, la atención de las urgencias, emergencias, desastres y catástrofes (Secretaría de Gestión de Riesgos, 2018).

Estos principios permiten a los municipios gestionar los riesgos cantonales, también para aliviar el sufrimiento de las personas afectadas o damnificadas y seguridad a la población en el territorio. Los riesgos que se identifiquen se pueden gestionar de manera específica para cada uno de ellos, en esta diferencia radica en la gestión de cada uno de ellos. Actualmente, los municipios deberían construir estrategias para resolver los riesgos más complejos que se presenten según la realidad del territorio, a falta de una guía o metodología para el manejo de estos casos que se presentan en los cantones. Pero con las gestiones realizadas bajo estos principios, aportan a mejorar la cobertura de proporcionar los productos y servicios bajo su competencia.

\section{Gestión de Riesgos en el ámbito de la Ad- ministración Pública}

Los factores de pobreza que se evidencia en una población y el entorno en que habitan dentro de una zona urbana o rural, es clave para un gobierno, porque se ubican en lugares y viviendas poco seguras, la infraestructura pública es baja en cobertura, los ingresos por familia suelen ser inestables; es por este grupo que hay que trabajar en una cultura para prevenir riesgos.

El Ecuador, asume desde el 2008 la gestión de riesgos en la constitución (Art. 389 y 390) y actualmente se evidencia en la política 1.11 de los Objetivos Nacionales de Desarrollo (Secretaría Técnica Planifica Ecuador, 2017). Los mismos que han sido establecidas y asumidas por los gobiernos cantonales por medio de la COOTAD en el Art. 140 y Art. 466 determina que "se le asigna un valor clave al ordenamiento territorial en la Reducción de Riesgo de Desastres" (SGR/ ECHO/UNISDR, 2012, pág. 58), integrados con los Objetivos de Desarrollo Sostenible que se enfoca en la filosofía de gestión integral de riesgos para minimizar la inseguridad por desastres naturales o antrópicas (11. Ciudades y comunidades sostenibles) (Naciones Unidas/CEPAL/ILPES, 2018).

En el ámbito de la gestión de riesgos, lo lidera el Servicio Nacional de Gestión de Riesgos y Emergencias-SNGRE (anteriormente Secretaría de Gestión de Riesgos-SGR) es el ente rector a nivel nacional, por lo que asesoran, norman, regulan y coordinan las acciones que ejecutan los intermediarios del Sistema Nacional Descentralizado de Gestión de Riesgos-SNDGR en busca de gestionar el riesgo ante la generación de un evento peligroso; liderado por el SNGRE, Io integran las UGR de todas los organismos públicos y privados a escala local, regional y nacional, adicional las instituciones científicas que monitorean y examinan las amenazas y vulnerabilidades, mecanismos de coordinación, COE, entre otros componentes (Secretaría de Gestión de Riesgos, 2014).

Para regular el funcionamiento en todos los 
estratos de gobierno en las competencias de planificación de desarrollo y las finanzas públicas, organización territorial, programación presupuestaria y todos los recursos públicos se establece en el Art. 64 de la COPLAFIP (Asamblea Nacional, 2010), en donde se busca que se incorpore el enfoque ambiental y de la gestión de riesgos para la inversión pública (programas y proyectos). (SGR/ECHO/UNISDR, 2012)

El 16 de abril de 2016, por la ocurrencia de un sismo al norte de la provincia de Manabí, puso a prueba toda la planificación realizada con las instituciones que integran el SNDGR, liderada por SGR, dejando aprendizajes para todas las instituciones presentes en el país. Con esa experiencia, se inicia con los ajustes en la estructura del COE en donde se realiza énfasis en las acciones de prevención para reducir el nivel de los impactos negativos de los desastres y a la preparación como la base de la gestión de los riesgos (Secretaría de Gestión de Riesgos, 2017).

Cuando ocurren los desastres supera las capacidades o recursos que existe en el territorio, considerado así en las leyes o políticas en un entorno nacional, estos sucesos han generado que las instituciones u organismos involucrados realicen procesos para transferir las responsabilidad y el poder a las autoridades de un territorio desde el enfoque de operaciones, resulta que gestionar el impacto de los desastres puede ser difícil con la carga política (Federación Internacional de Sociedades de la Cruz Roja y de la Media Luna Roja, 2015).

En muchos países, en las acciones para minimizar los riesgos por desastres, se han delegado las funciones a las autoridades locales, en algunos casos sin la asignación de recursos o del personal técnico necesario (Federación Internacional de Sociedades de la Cruz Roja y de la Media Luna Roja, 2015).
A nivel internacional existen herramientas y metodologías que han sido emitidas por las Naciones Unidad, enfocadas en la prevención de riesgos frente a los desastres de origen natural o por actividades humanas; en busca de que los territorios y los gobiernos tengan buenas prácticas con base a las experiencias de otros países que han sufrido por los desastres.

Es conveniente recalcar que dentro del ámbito de gestión de riesgos se trabaja en tres fases según el ciclo de gestión de riesgos, que son: 


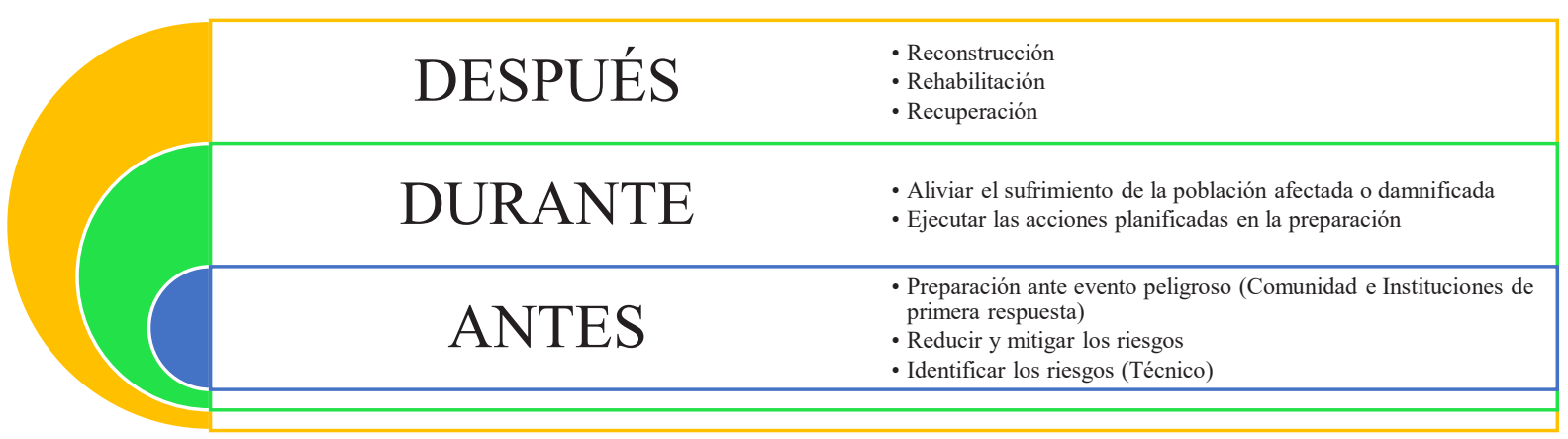

Figura II. Fases de la Gestión del Riesgo de Desastres. En cada una de ellas se ejecutan acciones ante el incidente de un evento peligroso.

Fuente: CEPAL, 2018

Elaboración: Soriano, Liliana

Los gobiernos nacionales han pasado la responsabilidad a los gobiernos cantonales (Municipios) que existen dentro de una zona urbana o rural para que asuman la gestión social y administrativa frente a los riesgos que existan o puedan existir en un territorio, en donde se realiza una línea base de lo que actualmente existe de información de territorio para iniciar.

Las Unidades de Gestión de Riesgos (UGR) en los Municipios y su conformación, según la SNGRE

Los Municipios o llamados también Gobiernos Autónomos Descentralizados-GAD a nivel cantonal o Municipal, en Ecuador existen 221 cantones en total y de los cuales 174 GAD Municipales tienen una población menor a los 50.000 habitantes, por lo que reciben del gobierno nacional un presupuesto menor en comparación a los gobiernos cantonales con mayor población. Todos los municipios a nivel de Ecuador fueron clasificados por el Ministerio de Trabajo en el año 2015; siendo A, municipios con mayor población -Quito y Guayaquil- y D con un número de población más baja (Ministerio de Trabajo, 2015).

Los 174 gobiernos cantonales con menor población, los de clasificación D, son los que presentan dificultades para cumplir con los estipulado en el año 2015 por la entidad rectora, actualmente el Servicio Nacional de Gestión de Riesgos y Emergencias, el cual emitió la resolución SGR-044-2015, con las funciones y condiciones que deben desempeñar las UGR de los GAD a nivel cantonal, para que se transversalice dentro de sus competencias y se articule al SNDGR, la SGR (actual SNGRE) (2015) norma "se debe aplicar para todos los GAD cantonal" sin especificar la clasificación antes mencionada. En este documento se exige la estructura orgánica, perfiles profesionales, herramientas tecnológicas "básicas", entre otros.

A los gobiernos cantonales trabajan en reducir los riesgos dentro de su territorio, pero desde el aporte económico que se haya definido para este fin, desde el gobierno nacional son casi nulas o bajas. Es por ello se articulan las instituciones presentes dentro de un territorio o se busca el financiamiento internacional por medio de proyectos sociales.

Las funciones de las UGR a nivel cantonal, deberán usar la información de la SGR y de su institución, sobre las amenazas, escenarios de riesgos, vulnerabilidad, indicadores de riesgo y cualquier otro dato que requie- 
ran de las instituciones gubernamentales o científicas; el objetivo principal es que la gestión y planificación institucional, se incluya a la gestión de riesgos como un eje transversal (Secretaría de Gestión de Riesgos, 2015, pág. 2).

En la Resolución SGR-044-2015, presenta una estructura organizacional para las UGR, en donde manifiesta que es "una línea base para conformar las UGR de un GAD" (Secretaría de Gestión de Riesgos, 2015, pág. 16), la misma que se divide en tres áreas que son: Monitoreo de Eventos Adversos, Preparación y Respuesta, Análisis y Reducción de Riesgos (Secretaría de Gestión de Riesgos, 2015, págs. 16-20). Además menciona que la estructura de conformación dependerá del número de habitantes, los ti- pos de amenazas registrados, la frecuencia e intensidad de las amenazas o desastres que ocurran, de los recursos económicos para afrontar sus necesidades y la política de su máxima autoridad (Secretaría de Gestión de Riesgos, 2015).

Cada área tiene especificaciones sobre las funciones, el perfil del responsable, los conocimientos del responsable, funciones del responsable y los productos y servicios a ofrecer; incluyendo al coordinador/jefe o director del área. Sin descartar las funciones a cumplir como unidad (Secretaría de Gestión de Riesgos, 2015). A continuación se muestra los diferentes procesos que se debe ejecutar con sus respectivas metodologías:

\section{Manejo de metodologías por parte de la UGR cantonal}

Comité de Operaciones de Emergencia-COE

Voluntariado

Comité Comunitario de Gestión de Riesgos-CCGR

Evaluación Inicial de Necesidades-EVIN

Sistema de Comando de Incidentes-SCI

Cooperación Internacional para Proyectos en Gestión de Riesgos

Tabla i. Metodologías, Manuales, Guías o Instrumentos para el manejo de estructuras o para el levantamiento de información en campo.

Fuente: SGR, 2015

Elaboración: Soriano, Liliana

La Secretaría de Gestión de Riesgos (2015) establece a la UGR cantonal que cumpla con seis funciones:

Identificar los elementos esenciales para la reducción de riesgos y determinar los estándares y normas técnicas que correspondan en el ámbito de su competencia [...] Monitorear el cumplimiento de los estándares y normas técnicas en gestión [...] Identificación y gestión de albergues temporales [...] Determinar estrategias y acciones para reducir los riesgos acumulados y nue- vos en sus procesos agregadores de valor [...] Determinar las amenazas para las cuales deben preparar y actualizar planes de contingencia y entrenar al personal para su aplicación [...] Preparar planes anuales de reducción de riesgos con indicadores, metas y vigilar su cumplimiento (págs. 12-15). A lo largo de estos años desde la década de los 70, diversas organizaciones han aportado en la evolución del manejo de los desastres, inicialmente se enfocaron en el momento de actuar después de que sucedía un desastre, con él pasar de los años,

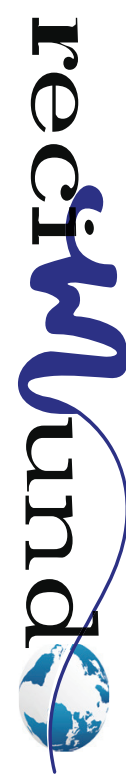


se evidencia que cuando se trabajaba con las comunidades para prevenir, estos sufrían menos daños y pérdidas.

\section{Desarrollo}

Cantón Salinas: Medidas de Acción Preventivas frente a Terremotos y Tsunami

En el año 2015, el Ministerio de Trabajo realizó una clasificación Municipal, el cantón Salinas de la provincia de Santa Elena, según esta clasificación, se encuentra dentro del grupo D. Salinas, tiene una población de 68675 habitantes según el censo 2010 del INEC, de los cuales 33239 son mujeres y 35436 son hombres. En la proyección de la población por cantón de la misma institución se visualiza que para el 2019 existirían 92017 habitantes y que para el 2020 este se incrementaría con 2573 hab. (94590 hab.), a este dato habría que descartar las pérdidas de vidas humanas por la pandemia actual. EI GAD Municipal de Salinas (2018) afirma que "La extensión del cantón Salinas es de 7356,70 ha, compuesta por $27 \mathrm{Km} 2$ en la cabecera cantonal y $37 \mathrm{Km} 2$ de la parroquia rural José Luis Tamayo y $10 \mathrm{Km} 2$ de la parroquia rural de Anconcito, dando un total de $74 \mathrm{Km} 2$ (...) La cabecera cantonal se encuentra en $<<$ La Puntilla de Santa Elena $>>$, considerando esta zona como turística, que es la principal actividad económica del cantón" (pág. 9).

En temporada alta, la población flotante aumenta hasta 3 veces, es vital la evacuación segura de los turistas y visitantes en el cantón Salinas. Existen aproximadamente 100 hoteles/hostales y 100 restaurantes. Existe infraestructura en los puertos pesqueros de Santa Rosa y Anconcito, como también laboratorios de larvas de camarón que tienen vulnerabilidad alta frente a un tsunami (GAD Municipal de Salinas, 2018).

Siendo Ecuador un territorio considerado para el origen natural de desastres con riesgo alto, especialmente en la zona costera por la presencia de la fosa oceánica, en el cual Salinas se encuentra a $60 \mathrm{Km}$ de esta, por lo que se encuentra en riesgo de sufrir por las afectaciones negativas de un sismo y/o tsunami, debido al proceso de subducción de las placas de Nazca por la Sudamericana.

Según los estudios de simulaciones realizados por el gobierno cantonal con el acompañamiento del ente rector y una agencia de cooperación internacional, un terremoto de 8 a 9 grados de magnitud puede generar un tsunami con olas de hasta 10 metros de altura, la población tendría entre 11 a 22 minutos para evacuar, antes de que llegue la primera ola, viéndose afectada aproximadamente el $80 \%$ del cantón.

El cantón Salinas, estima que los daños por desastres, debido a las medidas insuficientes de mitigación, en la red de alcantarillado, asentamientos humanos irregulares, pozos petroleros y líneas de conducción de gas y áreas de afloramiento.

Dentro de las herramientas que utilizan los municipios para las medidas en los procesos de gestión de riesgos específicamente para el decrecimiento es la Agenda de Reducción de Riesgos, en donde esta se enfoca en las fases de mitigación y preparación. Las medidas estructurales son de la mitigación, estas deben ser visibles. Y las medidas no estructurales son de preparación, dentro de la cual está la prevención.

Estas acciones de reducción de riesgo buscan desarrollar ciudades seguras y resilientes contra desastres y que contribuyan al fortalecimiento de los procesos de desarrollo sostenibles, según las normativas vigentes, competencias y responsabilidades en los ámbitos del territorio según corresponda, como los municipios a nivel cantonal. Salinas se ha enfocado en sismo y tsunami. La metodología para elaborar esta Agenda recopila información del Plan de Desarrollo y Ordenamiento Territorial vigente en el can- 
tón, con base a ello se toman las medidas a establecerse en el documento, en donde los integrantes del Comité de Operaciones de Emergencias, levantan esta información con la coordinación de la UGR del gobierno cantonal.

En el 2015, la SNGRE llevó a cabo actividades de sensibilización en 20 comunidades de las 50 planificadas para ese año. La UGR ejecutó talleres en 6 parroquias urbanas (4) y rurales (2) y en 5 áreas vulnerables. El documento estipula que la participación en los talleres es generalmente baja, especialmente de hombres.
Variable: Identificación y Análisis del riesgo en el territorio

Para establecer las amenazas existentes en una zona específica se puede iniciar, usando información y referencias oficiales del gobierno nacional y de los GAD (información documental, cartográfica y estadística), se debe realizar el levantamiento histórico de las amenazas ocurridas dentro del territorio, que han afectado o pueden afectar al desarrollo territorial, incluyendo datos como número de eventos peligrosos registrados (número de personas afectadas, desaparecidos, fallecidos y desaparecidos, costo de los daños, entre otros) (Servicio Nacional de Gestión de Riesgos y Emergencias, 2019).

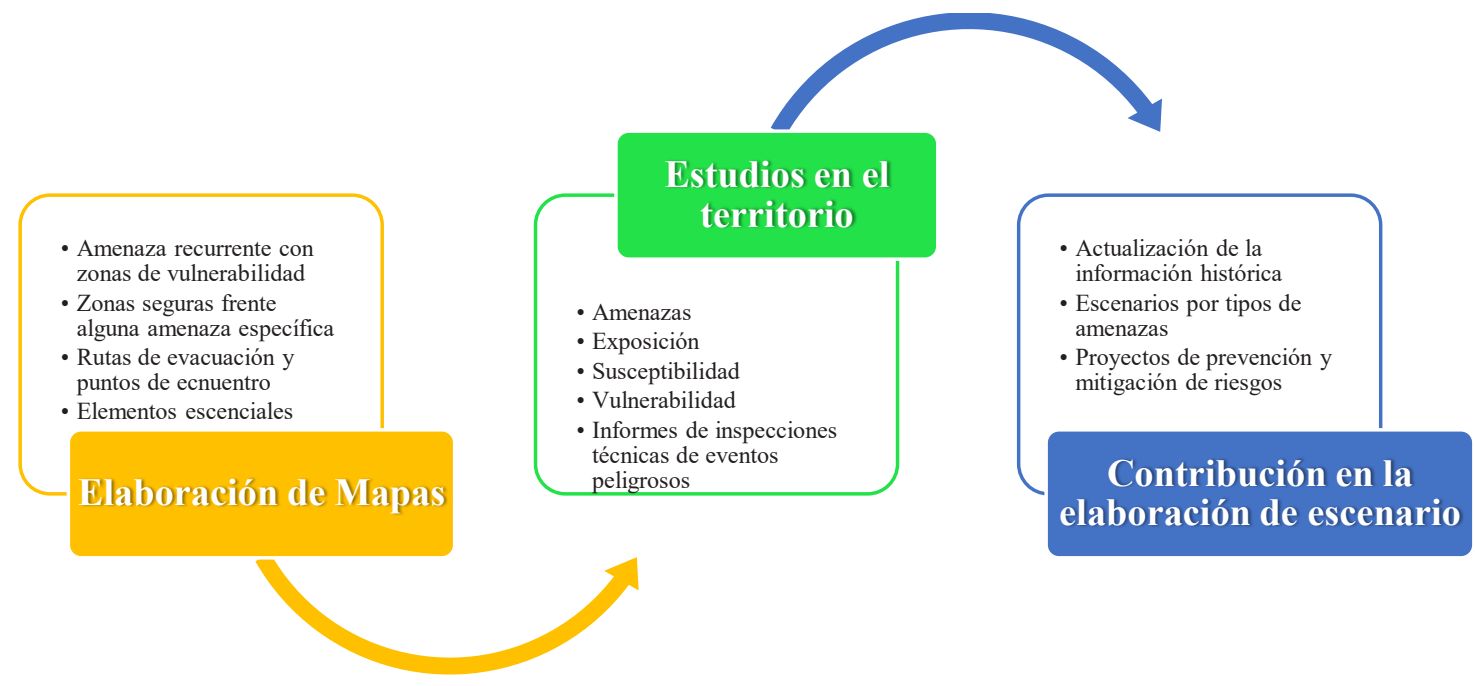

Figura III. Procesos en la Identificación y Análisis de Riesgos

Fuente: SNGRE, 2019

Elaboración: Soriano, Liliana

Elaborar mapas de susceptibilidad, con base a la capacidad económica y técnica de cada GAD, en donde se demarca las zonas que presente mayor afectación por alguna amenaza de origen natural o antrópica (zonas cercanas a las orillas de un río son más predispuestas a desbordase, por la topografía baja en comparación al resto del territorio, entre otros que puedan existir); incluyendo las zonas priorizadas con existen- cia de riesgo residual (Servicio Nacional de Gestión de Riesgos y Emergencias, 2019). En el ámbito nacional, existe una normativa de apoyo para esta variable en la Ley Orgánica de Ordenamiento Territorial, Uso y Gestión de Suelo, se busca su aplicación en los GAD a nivel cantonal con base a sus competencias todo lo relacionado a la planificación del desarrollo, ordenamiento territorial, obras, entre otros; en donde se

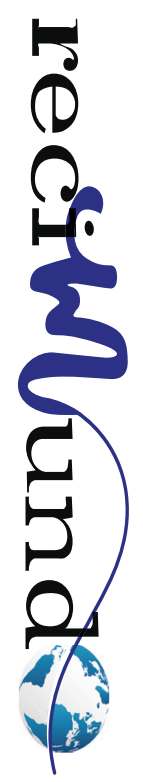


brinda las herramientas para articular acciones para propiciar un hábitat seguro y saludable, vivienda adecuada y digna en el desarrollo social y ambiental generando la inclusión del Buen Vivir en el desarrollo urbano (Asamblea Nacional, 2016).

La Subsecretaría de Hábitat y Asentamientos Humanos del MIDUVI y la Secretaría Nacional de Planificación y Desarrollo (2020), han realizado una propuesta de ley llamada Ley orgánica del Hábitat, Suelo y Vivienda, buscando que los GAD desarrollen su autonomía en donde se les permita la implementación de las políticas de suelo.

Actualmente existen lineamientos para agregar la gestión de riesgos en la planificación territorial, que deben elaborar los municipios, considerado como un eje transversal, dentro la planificación para el ordenamiento y desarrollo territorial, para evitar la aparición de nuevos riesgos, reducir las pérdidas y daños, que se podrían generar por los efectos negativos frente a los desastres, por medio del manejo de los riesgos presentes dentro del territorio (Servicio Nacional de Gestión de Riesgos y Emergencias, 2019).

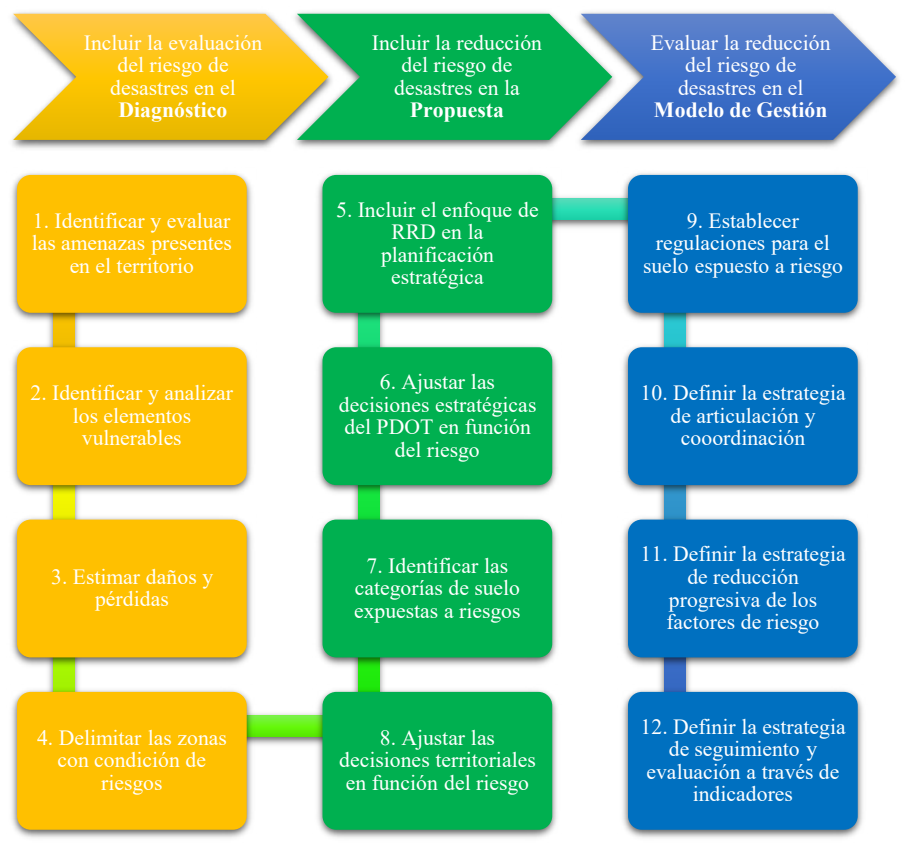

Desde el ámbito de sus competencias, los Gobiernos Autónomos Descentralizados (GAD), deberían generar información de un modelo de territorial actualizado, con enfoque cualitativo y cuantitativo, en donde se visibilice las pérdidas y daños que podrían ocasionar a la población, a los medios de vida, bienes y servicios en la dinámica de un territorio frente a un desastre; mediante el análisis de riesgo y la evaluación de los escenarios de los riesgos presentes en el mismo. (Servicio Nacional de Gestión de Riesgos y Emergencias, 2019)

Dentro del PDOT, se establecen las políticas territoriales, los objetivos estratégicos, las estrategias de articulación, la gestión de los programas y proyectos de inversión, el fortalecimiento a nivel institucional y social, y el incremento en la resiliencia de la colectividad (Servicio Nacional de Gestión de Riesgos y Emergencias, 2019, pág. 12). Se debería considerar el enfoque de la gestión de riesgos de desastres como el eje transversal en la planificación y en los procesos de desarrollo (Secretaría Técnica Planifica Ecuador, 2019, pág. 21).

Figura IV. Condiciones mínimas para la inclusión de la gestión del riesgo de desastres en los procesos de desarrollo territorial a nivel cantonal.

Fuente: SNGRE, 2019

Elaboración: Soriano, Liliana 
Estas condiciones se enfocan en el incremento progresivo del conocimiento sobre los riesgos presentes en el territorio, para lograr la ejecución de programas y proyectos para la reducir los riesgos por desastres, por medio de la transversalización de la GRD en el desarrollo territorial, con acciones para la reducción de riesgos estructurales (ampliación de la cobertura para el alcantarillado pluvial en zonas de riesgo por inundación por falta de drenaje o la construcción de obras civiles multipropósitos que permita a la población estar preparados ante los desastres) y no estructurales (fortalecimiento de capacidades en la comunidad o reforestación en zonas de riesgo mitigables), logrando el "cumplimiento a las políticas nacionales, a los Objetivos de Desarrollo Sostenible y al Marco de Sendai para la Reducción del Riesgo de Desastres" (Servicio Nacional de Gestión de Riesgos y Emergencias, 2019, pág. 14)

\section{Variable: Reducción de riesgos y Preparación ante eventos peligrosos}

Para la Estrategia Internacional del Riesgo de Desastres-EIRD de las Naciones Unidas (2018) propone que la Reducción del Riesgos de Desastres-RRD incluye la participación de toda la sociedad y del gobierno y todos los que integran el sector privado y profesional reducir los riesgos de desastres, las políticas de desarrollo poco sensatas aumentaran el riesgo y pérdidas que estos ocasionan.

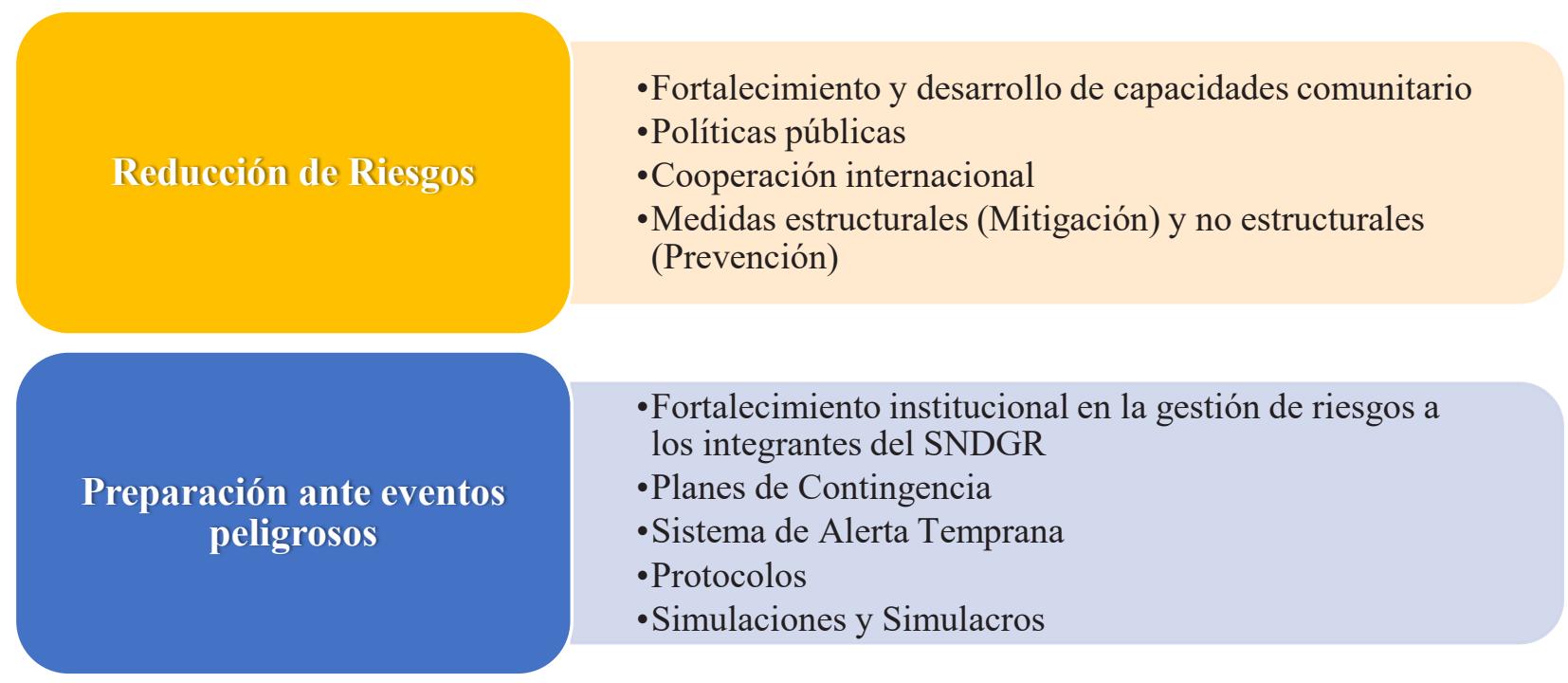

Figura V. Procesos de Reducción de Riesgos y de la Preparación ante eventos peligrosos

Fuente: SNGRE, 2015

Elaboración: Soriano, Liliana 
En la Gestión del Riesgos de Desasatres-GRD, a nivel cantonal, se trabaja con los barrios, las instituciones de primera respuesta o socorro para fortalezca las capacidades o las desarrolle para que la población tenga conocimiento y las aptitudes adecuadas para enfrentar cualquier evento peligroso recurrente que se pueda suscitar. Es aquí donde se puede organizar a la comunidad e incrementar la capacidad de estos, con el propósito de disminuir las pérdidas humanas y daños económicos y ambientales como consecuencia del impacto negativo del desastre. La responsabilidad principal en materia de reducción del riesgo de desastres le corresponde a las gobiernos, en los instrumentos legales internacionales lo especifica de manera clara, incluso los mismos, ignoran a las autoridades locales y a la sociedad civil en estas actividades para reducir los riesgos (Federación Internacional de Sociedades de la Cruz Roja y de la Media Luna Roja, 2015).

Para llevar a cabo las normativas en el territorio se requieren gestionar acciones, mediante la participación y coordinación de los representantes locales, en la realización de actividades para sensibilización, como campañas educomunicacionales, afiches, capacitaciones, vídeos, reuniones y visitas de campo para la identificación de zonas de riesgo. Involucrar a los actores en la participación de los procesos, para establecer actividades concretas, como el plan de desarrollo, el mapa de riesgos, simulacros y transferencias de conocimientos con el gobierno municipal para el fortalecimiento de las organización comunitaria (Bollin, Cárdenas, Hahn, \& Vatsa, 2003).

Desde el principio de transversalización los GAD deberían garantizar un modelo territorial centrado en la seguridad humana dentro del territorio. Lograr el desarrollo sostenible, por medio de acciones que van enfocadas a la precaución de generar nuevos riesgos, en la mitigación de los presentes y, en la gestión de los riesgos persistentes; todo contribuye a la consolidación de la resiliencia (Servicio Nacional de Gestión de Riesgos y Emergencias, 2019).

En general, es evidente que la población mundial tiende a concentrarse en las grandes ciudades, ¿Se puede evitar que sean propensas a los desastres?; se puede visibilizar en ella una urbanización de desastres y los que se derivan de los riesgos. La respuesta en un entorno urbano en casos de desastres en los países de ingresos bajos, en lo que por ende, la pobreza endémica justifica la existencia de vulnerabilidades a los desastres. A escala internacional, las organizaciones, los gobiernos nacionales y locales por medio de los servicios de seguridad y socorro tienen un proceso de aprendizaje lento al momento de trabajar con la población que no cuentan con los títulos de sus terrenos, que no están registrados o catastrado, sin documento alguno que valida su pertenencia; esto fomenta que las desigualdades se enfaticen incluso antes de que se suscite un desastre en los asentamientos ilegales (Federación Internacional de Sociedades de la Cruz Roja y de la Media Luna Roja, 2010).

Considerando que en esta variable de Preparación ante eventos peligrosos, se deben ejecutar acciones para fortalecer y desarrollar las capacidades de respuesta de las instituciones de primera respuesta o socorro, con la planificación de acciones articuladas para enfrentar los diferentes tipos de amenazas que existan en el registro histórico del territorio.

Es así como, las creencias y los comportamientos están ligados a los rasgos y a la personalidad como parte de la cultura, donde es conveniente evaluar el comportamiento de las instituciones como las de la población desde otra perspectiva en donde los factores que implican las actividades de preparación ante los desastres sean visibilizados, buscando ser prácticos al ejecutar las mismas (Federación Internacional de 
Sociedades de la Cruz Roja y de la Media Luna Roja, 2014).

En ese orden de ideas, a través de la ejecución de las acciones de preparación, se va orientado en mejorar el conocimiento, habilidades y destrezas (prevención, respuesta y recuperación) de manera efectiva frente a la adversidad de la ocurrencia de desastres probables, inminentes o presentes, se busca gestionar el riesgo residual (Servicio Nacional de Gestión de Riesgos y Emergencias, 2019).

\section{Variable: Recuperación pos desastre}

En la fase del después de un evento peligroso, el ente rector considera que se inicie un proceso para restituir las condiciones de vida aceptable y sostenible mediante la rehabilitación y la reconstrucción de infraestructura, bienes y servicios que se hayan destruido, deteriorado o interrumpido en la zona afectada (Ministerio de Educación/Secretaría Nacional de Gestión de Riesgos, 2010, pág. 24).

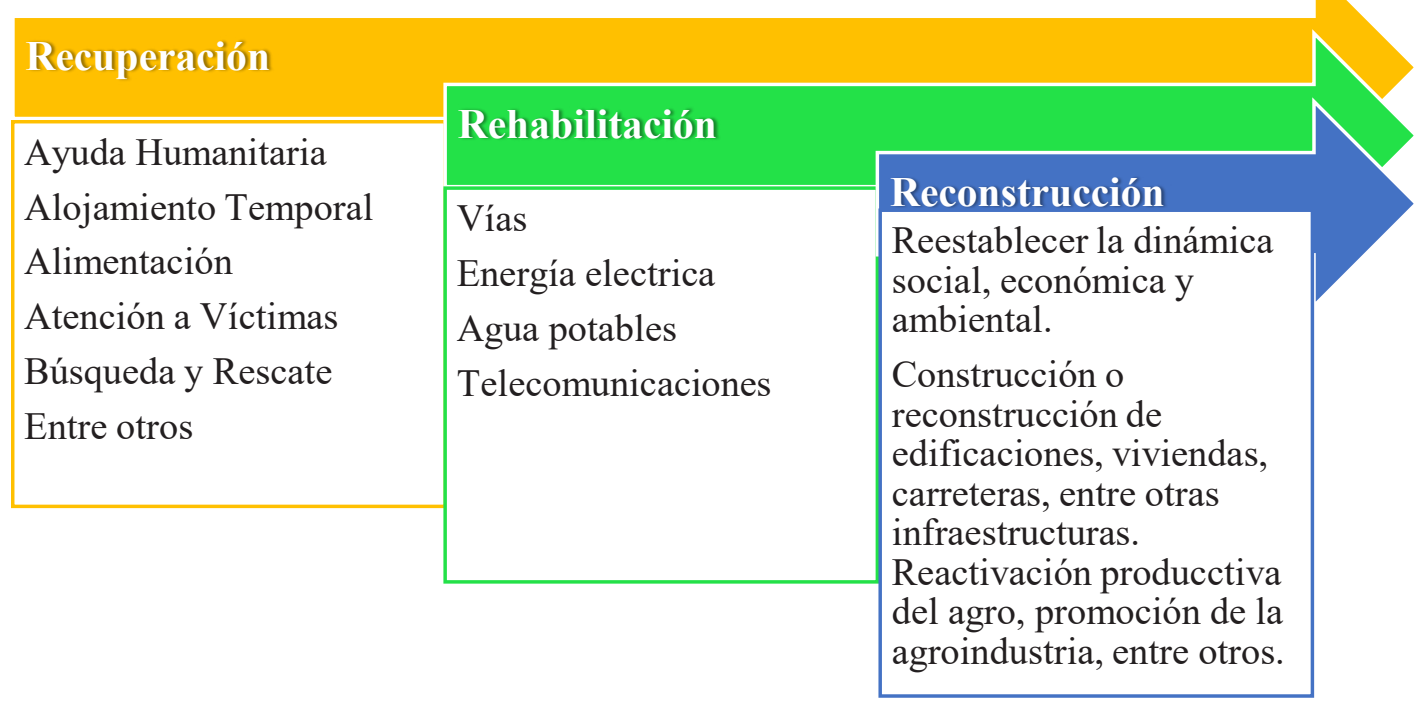

Figura VI. Procesos pos desastre, Recuperación.

Fuente: MINEDUC/SNGR, 2010

Elaboración: Soriano, Liliana

Para las familias de las zonas urbanas, el restablecimiento de sus medios de vida y la reconstrucción de sus viviendas, van en conjunto, porque este representa el hogar y la seguridad, y para la población activo es una posibilidad para poder acceder a un empleo con la opción de poder constituir su empresa familiar (Federación Internacional de Sociedades de la Cruz Roja y de la Media Luna Roja, 2010).
En el 2004 ocurrió un tsunami en el Océano Índico, devastando a muchas comunidades costeras, algunos de estos estaban ocupados por asentamientos inseguros. Los que sobrevivieron buscaban restablecer sus medios de vida y reconstruir sus viviendas, pero hay que recordar que es un proceso a largo plazo. Las organizaciones de seguridad y socorro por lo general se enfocan en lo que pueden hacer por las víctimas. Y

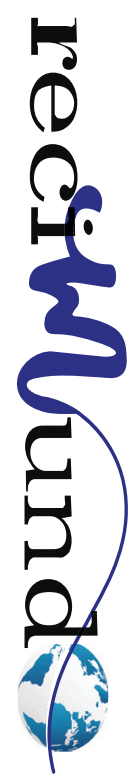


estas, no pueden conseguir terrenos en casos de desastres, porque suelen ser costosos. Las empresas inmobiliarias buscaban adquirir estos terrenos luego del desastre, siendo una buena oportunidad, con sus conexiones, tal como se visibilizó ese año. Aquí que se hizo caso omiso a las personas afectadas, en donde ellas son el principal pilar para saber dónde y cómo reconstruir (Federación Internacional de Sociedades de la Cruz Roja y de la Media Luna Roja, 2010).

En los desastres se puede aprovechar las oportunidades de cambio, en el proceso de recuperación, para el desarrollo del territorio de manera sostenible, para esto se debe ir más allá de reparar una infraestructura afectada, que responde a las necesidades urgentes de la ciudadanía y los esfuerzos por recuperar y construir nuevas bases para el desarrollo y trabajar en los riesgos que puedan generar a futuro la insostenibilidad del territorio (Programa de Naciones Unidas para el Desarrollo-PNUD, 2009).

Desde 1999, en el cantón Cevallos tuvo la caída de cenizas por el proceso eruptivo del volcán Tungurahua que duró algunos años. En el 2008, cuando recién se institucionalizó la gestión de riesgos en el país, tuvo que enfrentar las inundaciones que se presentaron en 13 provincias de las 24 existentes, fue la primera experiencia para la administración pública en la recuperación pos desastres (Programa de Naciones Unidas para el Desarrollo-PNUD, 2009).

En el 2016, al norte de la provincia de Manabí se suscitó un sismo de magnitud fuerte, cuyo impacto ocasionó daños materiales, económico, social y ambiental; las pérdidas de vidas humanas irreparables fue el mayor huella dejada en el ámbito psicosocial, con esta experiencia el actual Servicio Nacional de Gestión de Riesgos y Emergencias ha mejorado los procesos para la recuperación pos desastres pero aún se necesita que estos procesos sean eficaces (Secretaría de
Gestión de Riesgos, 2017).

\section{Metodología}

La presente investigación es desde un enfoque analítico-descriptivo con una modalidad documental, es previa a la definitiva, una base de inicio para establecer aspectos vinculados con el tema, se busca generar información sobre los productos y servicios que deben ofrecer las Unidades de Gestión de Riesgos -UGR cantonal sin especificar la clasificación que tenga el municipio al que pertenecen, pero queremos centrarnos en los de clasificación D por su bajo presupuesto y densidad demográfica.

Para ello nos hemos enfocado en los registros de hechos suscitados en el ámbito de la gestión de riesgo de desastres y los procesos institucionales desde la política pública que han ejecutado desde la administración pública para gestionar estos riesgos por desastres. Como país la visión es tener cero pérdidas de vidas humanas por eventos que se pueden suscitar siendo este territorio considerado multi-amenazas, en donde se ha institucionalizado este ámbito desde hace doce años de gestión pública. El propósito de este estudio de caso es evaluar las medidas de acción de prevención frente a los riesgos por desastres de origen natural o por actividades humanas, en la población, que ejecuta la UGR del gobierno cantonal. Como instrumento de recolección de los datos se utilizará las recomendaciones obtenidas de los documentos emitidos por la institución desde el 2018 hasta junio 2020.Siendo proyectos de educación a la comunidad en general con la intención de desarrollar y fortalecer sus capacidades de actuación frente a los desastres de origen natural o por actividades humanas.

La metodología consistió en revisar y analizar los hechos y las políticas desde el entorno internacional hasta el nacional, en donde el ente rector que lidera el Sistema Nacional Descentralizado de Gestión de Riesgos (SNDGR), desde el 2008 ha venido 
implementando políticas para el manejo administrativo-operativo a nivel nacional, en donde aterrizarlo de forma generalizada a nivel cantonal les ha tomado hasta el año 2015.

Considerando la normativa vigente para conformar las UGR cantonales en donde se establece procesos administrativos y la generación de productos y servicios técnicos, información que se debería manejar en cada área como también los equipos tecnológicos a usar.

Los municipios de clasificación $\mathrm{D}$, considerando el registro histórico de la ocurrencia de eventos peligrosos, podrían proporcionar los productos y servicios establecido por el ente rector; cabe recalcar que según la normativa vigente, se estipula una estructura organizativa base y los complementa con perfiles profesionales técnicos con sus respectivos equipos tecnológicos para cumplir con estos requerimientos.

Se estableció para este estudio las variables según la cobertura de los productos y servicios, que corresponden a una de las fases del ciclo de gestión de riesgos (antes, durante y después) en que se debería tomar acciones según la área de Reducción de riesgos que lo compone la Mitigación, la Prevención y la Preparación ante eventos peligrosos. Nuestro enfoque será en las acciones preventivas.

\section{Resultados}

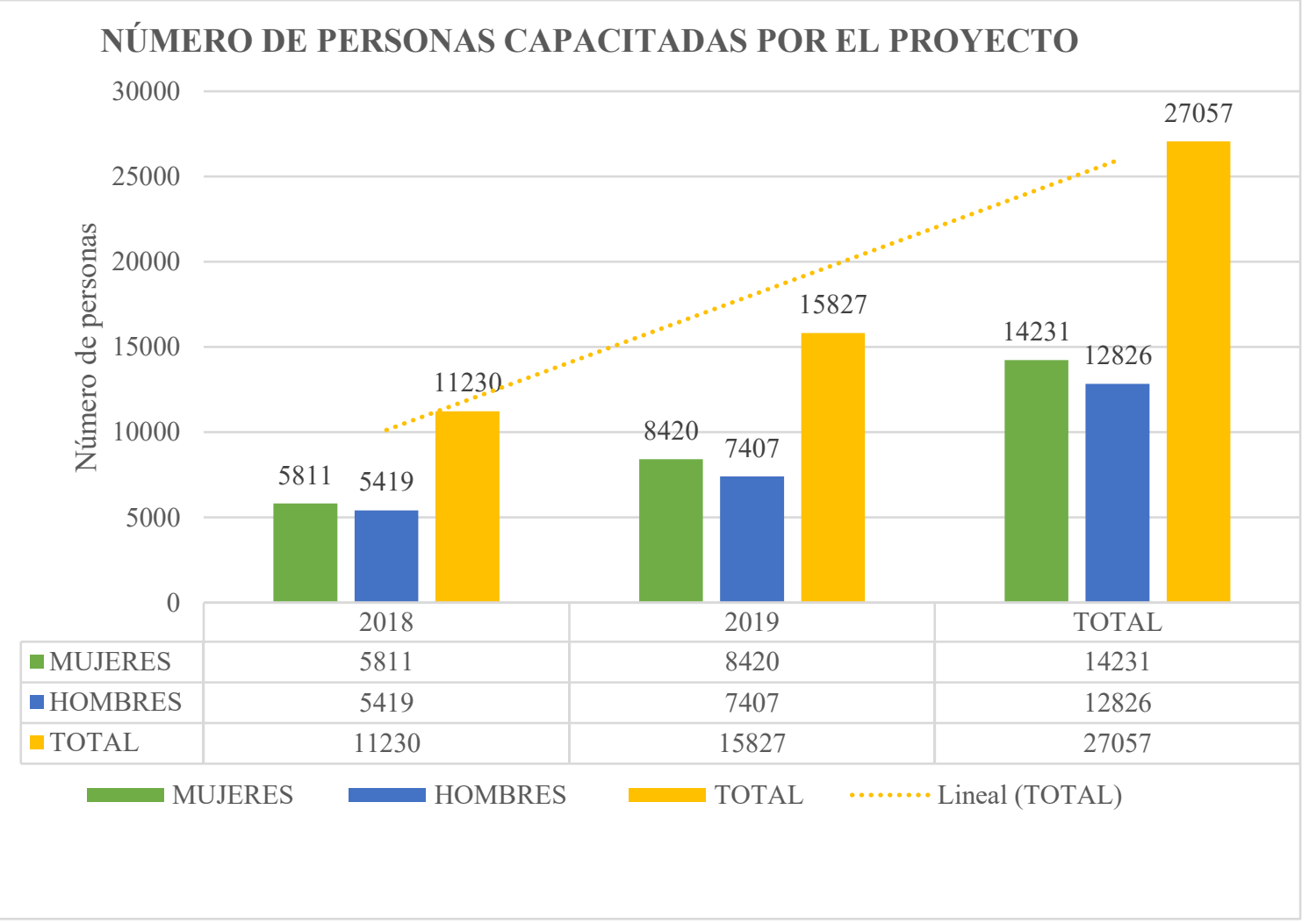

Figura VII. Participación de la comunidad en capacitaciones en el proyecto social financiado por cooperación internacional (Agosto 2018 a Diciembre 2019).

Fuente: PCSR Salinas, 2019

Elaboración: Soriano, Liliana 
El convenio entre el gobierno cantonal y la agencia de cooperación internacional, ha permitido que desde el 2015 se levante información del territorio para la generación mapas específicos en sismo y tsunami. A partir de esta información se puede iniciar con las acciones para mitigar y prevenir los riesgos existentes. Para ello se implementa la metodología de la ARR 2018.

Por medio de un proyecto social frente a terremotos y tsunami, se logró incrementar el conocimiento de las rutas de evacuación y puntos de encuentros en la comunidad. Por la pandemia que se está atravesando a nivel mundial, se paraliza estas acciones. Sólo 5 de los 174 municipios de clasificación $\mathrm{D}$, están dentro de este proyecto, financiado por cooperación internacional, con el acompañamiento del ente rector, que se ejecuta desde 2015, que fue interrumpido por el sismo del 2016 ocurrido al norte de nuestras costas. Beneficiando así a otros municipios que fueron omitidos de los municipios pilotos.

Todo este proceso de la nueva ARR que fue aprobada por la autoridad del territorio en diciembre de 2018, fue como parte de la ejecución del Proyecto para la Construcción de Ciudades Seguras y Resilientes contra Desastres por Terremotos y Tsunami (PCSR). Con el apoyo de la SNGRE y JICA. Dentro de este proyecto se encuentra otros cantones de Atacames, Portoviejo, Esmeraldas, Sucre, Santa Elena y Santa Cruz.

En el 2015, se elaboró una ARR con enfoque en elementos esenciales enfocada al Fenómeno El Niño, esta permitió que se pueda obtener información para actualizarla para sismo y tsunami. Inicialmente se menciona que en el estudio de línea base, los habitantes demostraron su desconocimiento sobre las rutas de evacuación. Con base a ello es que durante el PSCR ha trabajado en reforzar estos conocimientos.

El gobierno cantonal planificó en el docu- mento que va a mejorar los incentivos para fomentar la participación en este tipo de actividades, desarrollar material de difusión con enfoque educativo como apoyo en las actividades de prevención, elevar un mapa de evacuación ante tsunami en su sitio web. Su enfoque es a estudiantes, adultos, grupos de atención prioritaria y turistas.

Siendo la gestión de riesgos un eje trasversal, todas las instituciones tienen responsabilidades según sus competencias, por ello la articulación a nivel interinstitucional es clave en la ejecución de acciones antes, durante y después de un desastre. Dentro de la participación ciudadana, estipuló el gobierno cantonal establecer un sistema de voluntariado y la organización comunitaria a nivel cantonal.

Desde el enfoque para reducir pérdidas humanas, se ha instalado un Sistema de Alerta Temprana (SAT) y señalética para fortalecer la capacidad de respuesta de la población. Planificó realizar un estudio para la construcción de una torre de evacuación, montículo elevado y la ejecución de simulacros a gran escala en donde se incluya a los grupos de atención prioritaria.

Se recomendó en la $A R R$ que se incremente el número de servidores públicos a la UGR, hasta el 2018, la cantidad del personal en esta área eran 6 (seis). Al reflejar las acciones de la ARR en el PDOT, permite asegurar fondos, para las medidas planificadas, por el municipio. Las acciones en las que intervienen de forma directa por competencias de otras instituciones se articulan entre sí.

\section{Conclusiones}

La descentralización en la gestión de riesgo genera una necesidad en los gobiernos cantonales de clasificación D para desarrollar capacidades en la articulación de acciones preventivas interinstitucionales para reducir los riesgos presentes en el territorio. Estos gobiernos lideran el sistema a nivel 
local en donde deben brindar seguridad y un desarrollo sostenible en el área.

El análisis revela que existe una carencia en la identificación, análisis de riesgos y vulnerabilidades en el desarrollo y ordenamiento territorial generando vulnerabilidades en la población. Los gobiernos cantonales construyen a mediano plazo (4 años) esta planificación, adicional se enfoca en los riesgos recurrentes escaseando de integralidad. Para fortalecer las acciones a futuro se requiere de la generación de mapa específicos en riesgos y vulnerabilidades, considerando los riesgos compuestos.

El presupuesto asignado por el gobierno nacional a los gobiernos cantonales para la ejecución de las competencias, según las políticas y normativas, la gestión de riesgo no cuenta con partida presupuestaria para gastos por imprevistos de desastres. Considerando lo mencionado, es imprescindible que se desarrolle capacidades institucionales para gestionar el financiamiento nacional o internacional por medio de proyectos para el desarrollo social (cantón Salinas), así como incluir una planificación financiera dentro del plan de desarrollo.

Es indispensable que se evalúe los perfiles profesionales requeridos por el ente rector, para los gobiernos cantonales de clasificación $\mathrm{D}$, tanto del Jefe como el del área Análisis y Reducción de Riesgos o Monitoreo de Eventos Adversos, para el cumplimiento de los productos y servicios requeridos; inicialmente es inevitable realizar un contrato para generar productos con la identificación, análisis de riesgos y vulnerabilidades; incluyendo aptitudes de gestión.

Según la propuesta base del ente rector en la estructura orgánica, los gobiernos cantonales de clase $D$, pueden priorizar la contratación considerando la realidad del territorio, la existencia del perfil profesional, el registro histórico de las amenazas y de las vulnerabilidades presentes en la zona. Den- tro del presupuesto que el municipio asigne a la unidad se desglosaría el sueldo de estos profesionales.

El ente rector podría brindar una guía o metodología dirigida a los municipios como lo tiene Colombia para que puedan administrar, gestionar la operatividad y tecnificar el área de gestión de riesgos. Es preciso que estos gobiernos se empoderen en la especialización de los procesos y se enfoquen en tener los conocimientos necesarios y gestionar financiamiento con lo que no pueda acceder con el presupuesto aplicando los principios aplicados en gestión de riesgo.

Es recomendable que los gobiernos cantonales elaboren articuladamente la Agenda de Reducción de Riesgos, más allá de los riesgos recurrentes, este documento es una iniciativa que genera confianza en la búsqueda del financiamiento nacional o internacional. En conjunto se puede crear proyectos para fortalecer a la zona con acciones preventivas frente a los desastres. Una población preparada para responder ante los riesgos, reduce el incremento de pérdidas y daños.

La gobernanza del riesgo, frente al riesgo sanitario actual, ha puesto en evidencia la falta de practicidad al momento de ejecutar los instrumentos de planificación frente a las circunstancias adversas. La gobernanza y la institucionalidad deben ser fortalecidos en el trabajo transversal de la gestión de riesgos incluyendo los riesgos compuestos. Es preciso que se identifique los datos para que se genere indicadores de gestión de impacto y por resultados, en busca de facilitar la toma de decisiones de las autoridades cantonales en la prevención, mitigación y en el abordaje de los desastres que se pueden suscitar en el área (Ver Anexo IV). Construir con la ciudadanía mecanismos para fortalecer y desarrollar sus capacidades para adaptarse y mitigar las vulnerabilidades presentes y futuras, ayudará a

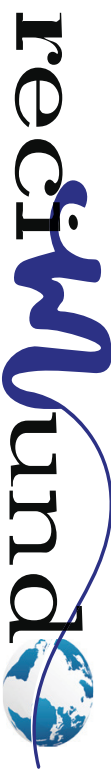


mejorar el desarrollo sostenible y seguro del área. Es un trabajo que requiere tiempo para que se refleje los resultados en las conductas idóneas de resiliencia en la población.

\section{Bibliografía}

Asamblea Nacional. (19 de octubre de 2010). R.O. 303. Código Orgánico de Organización Territorial, Autonomía y Descentralización. Quito, Ecuador: Registro Oficial.

Asamblea Nacional. (22 de octubre de 2010). R.O. 306. Código Orgánico de Planificación y Finanzas Públicas. Quito, Ecuador: Registro Oficial. Recuperado el Noviembre de 2019, de https:// www.finanzas.gob.ec/wp-content/uploads/downloads/2012/09/CODIGO_PLANIFICACION_FINAZAS.pdf

Asamblea Nacional. (21 de enero de 2014). R.O. 166. Ley Orgánica Reformatoria al Código Orgánico de Organización Territorial, Autonomía y Descentralización. Quito, Ecuador: Registro Oficial. Recuperado el Marzo de 2020, de https://www. gporellana.gob.ec/wp-content/uploads/2015/03/ LEY-ORG\%C3\%81NICA-REFORMATORIA-AL.pdf

Asamblea Nacional. (5 de julio de 2016). R.O. 790. Ley Orgánica de Ordenamiento Territorial, Uso y Gestión de Suelo. Quito, Ecuador: Registro Oficial. Recuperado el Enero de 2020, de https://www.habitatyvivienda.gob.ec/wp-content/uploads/downloads/2016/08/Ley-Organica-de-Ordenamiento-Territorial-Uso-y-Gestion-de-Suelo1.pdf

Bollin, C., Cárdenas, C., Hahn, H., \& Vatsa, K. (2003). Gestión de Riesgo de Desastres por Comunidades y Gobiernos Locales. Washington D.C.: Banco Interamericano de Desarrollo. Obtenido de https:// www.researchgate.net/publication/254423062_ Gestion_de_Riesgo_de_Desastres_por_Comunidades_y_Gobiernos_Locales

Corporación OSSO-Colombia. (2010). Ecuador - Sistema de Información de desastres y emergencias. Obtenido de Proyecto Desinventar: https://www. desinventar.net/DesInventar/profiletab.jsp?countrycode $=$ ecu\&continue $=y$

EIRD-Naciones Unidas. (2009). UNISDR Terminología sobre Reducción del Riesgo de Desastres. Recuperado el Mayo de 2020, de https://www.unisdr. org/files/7817_UNISDRTerminologySpanish.pdf

EIRD-Naciones Unidas. (2018). Estrategia Internacional para la Reducción del Riesgo de Desastres. Recuperado el 11 de Mayo de 2020, de https:// www.eird.org/americas/

Federación Internacional de Sociedades de la Cruz Roja y de la Media Luna Roja. (2010). Informe Mundial sobre Desastres. Ginebra, Suiza: Federación Internacional. Obtenido de https://www. ifrc.org/PageFiles/99873/Spanish/WDR2010-summary-SP.pdf

Federación Internacional de Sociedades de la Cruz Roja y de la Media Luna Roja. (2014). Informe Mundial sobre Desastres-Cultura y Riesgo. Ginebra, Suiza: Federación Internacional. Obtenido de https://www.ifrc.org/es/publicaciones/world-disasters-report/world-disasters-report-2014/

Federación Internacional de Sociedades de la Cruz Roja y de la Media Luna Roja. (2015). Informe Mundial de Desastres-Resumen-Los Agentes Iocales en el centro de la acción humanitaria eficaz. Ginebra, Suiza: Federación Internacional. Obtenido de http://ifrc-media.org/interactive/wp-content/ uploads/2015/09/1293604-WDR-summary-2015SP_LR-embargo.pdf

Federación Internacional de Sociedades de la Cruz Roja y de la Media Luna Roja. (2016). Informe Munidal de Desastres-Resumen-Capacidad de resistencia y recuperación: Salvar vidas hoy, invertir en el mañana. Ginebra, Suiza: Federación Internacional. Obtenido de https://www.ifrc.org/Global/Documents/Secretariat/201610/1304405-World\%20 Disaster\%20Resumes\%202016_Sp_LR.pdf

Gellert-de Pinto, G.-I. (2012). El cambio de paradigma: de la atenciónde desastres a la gestión del riesgo. Boletín Científico Sapiens Research Group, 2 (1), 13-17. Obtenido de https://www.srg.com.co/ bcsr/index.php/bcsr/article/view/8/8

Keipi, K., Mora Castro, S., \& Bastidas, P. (2005). Gestión de riesgo de amenazas naturales en proyectos de desarrollo-Lista de preguntas de verificación ("Checklist"). Washington, D.C.: Banco Interamericano de Desarrollo. Obtenido de https:// www.eird.org/cd/toolkit08/material/proteccion-infraestructura/gestion_de_riesgo_de_amenaza/8_ gestion_de_riesgo.pdf

Ministerio de Desarrollo Urbano y Vivienda-MIDUVI. (2020). Ley de Suelo, Hábitat y Vivienda. Obtenido de https://www.habitatyvivienda.gob.ec/ ley-de-suelo-habitat-y-vivienda/

Ministerio de Educación/Secretaría Nacional de Gestión de Riesgos. (2010). Plan Institucional de Emergencias para Centros Educativos-Preparémonos para manejar mejor las emergencias y desastres. Quito.

Ministerio de Trabajo. (febrero de 2015). Clasifica- 
ción Municipal. Recuperado el Marzo de 2020, de http://www.trabajo.gob.ec/wp-content/uploads/ downloads/2015/02/Clasificaci\%C3\%B3n-Municipal.pdf

Naciones Unidas/CEPAL/ILPES. (2018). Observatorio Regional de Planificación para el Desarrollo de América Latina y el Caribe. Obtenido de https:// observatorioplanificacion.cepal.org/es/planes/ plan-nacional-de-desarrollo-2017-2021-toda-unavida-de-ecuador

Programa de Naciones Unidas para el DesarroIlo-PNUD. (2009). Aprendiendo de la experiencia para planificar la recuperación-Sistematización de casos de recuperación en Ecuador.

Secretaría de Gestión de Riesgos. (2014). Manual del Comité de Gestión de Riesgos. Samborondón, Ecuador: Secretaría de Gestión de Riesgos.

Secretaría de Gestión de Riesgos. (2015). Conformación Organizacional de las Unidades de Gestión de Riesgos en los Gobiernos Autónomos Descentralizados Cantonales. Obtenido de https://www.gestionderiesgos.gob.ec/wp-content/ uploads/downloads/2015/09/Normativa-Resolucion-SGR-044-2015.pdf

Secretaría de Gestión de Riesgos. (2017). Manual del Comité de Operaciones de Emergencia. Samborondón, Ecuador: Secretaría de Gestión de Riesgos. Recuperado el 2019, de https://www. gestionderiesgos.gob.ec/wp-content/uploads/ downloads/2017/09/Manual-del-COE.pdf

Secretaría de Gestión de Riesgos. (2018). Glosario de términos de gestión de riesgos de desastres-Guía de consulta. Samborondón, Ecuador: Secretaría de Gestión de Riesgos. Recuperado el 2019, de https://www.gestionderiesgos.gob.ec/wp-content/ uploads/downloads/2019/01/GLOSARIO-DE-T\%C3\%89RMINOS-DE-GESTI\%C3\%93N-DE-RIESGOS-DE-DESASTRES-GUIA-DE-CONSULTA.pdf

Secretaría de Gestión de Riesgos. (2018). Plan Nacional de Respuesta ante Desastres. Samborondón, Ecuador: Secretaría de Gestión de Riesgos. Obtenido de https://www.gestionderiesgos. gob.ec/wp-content/uploads/downloads/2018/08/ Plan-Nacional-de-Respuesta-SGR-RespondeEC. pdf

Secretaría Nacional de Gestión de Riesgos. (2010). Guía Comunitaria de Gestión de Riesgos. Quito, Ecuador: Secretaría Nacional de Gestión de Riesgos. Obtenido de https://www.gestionderiesgos. gob.ec/wp-content/uploads/downloads/2012/07/ guia_comunitaria_gestion_riesgos.pdf

Secretaría Técnica Planifica Ecuador. (22 de septiembre de 2017). Plan Nacional de Desarrollo 2017-2021-Toda una vida. Recuperado el Febrero de 2020, de https://www.planificacion.gob.ec/ wp-content/uploads/downloads/2017/10/PNBV26-OCT-FINAL_OK.compressed1.pdf

Secretaría Técnica Planifica Ecuador. (Julio de 2019). Guía para la formulación/actualización del Plan de Desarrollo y Ordenamiento Territorial (PDOT) Cantonal. Quito, Ecuador: Secretaría Técnica Planifica Ecuador. Recuperado el Mayo de 2020, de https:// www. planificacion.gob.ec/wp-content/uploads/ downloads/2019/08/GUIA-CANTONAL-FINAL-.pdf

Servicio Nacional de Gestión de Riesgos y Emergencias. (Julio de 2019). Lineamientos para incluir la gestión del riesgo de desastres en el Plan de Desarrollo y Ordenamiento Territorial (PDOT). Samborondón, Ecuador: Servicio Nacional de Gestión de Riesgos y Emergencias. Recuperado el Mayo de 2020, de https://www. planificacion. gob.ec/wp-content/uploads/downloads/2019/09/ Caja-de-herramientas-Riesgos.pdf

SGR/ECHO/UNISDR. (2012). Ecuador: Referencias básicas para la gestión de riesgos (Emilio Ochoa Moreno ed.). Quito, Ecuador: Secretaría de Gestión de Riesgos-SGR. Recuperado el Mayo de 2020, de http://dipecholac.net/docs/files/196-ecuador-referencias-basicas-para-la-gestion-de-riesgos-2013-2014.pdf

USAID. (2012). Curso Básico Sistema de Comando de Incidentes-Material de Referencia. Recuperado el 2019, de http://bvpad.indeci.gob.pe/html/es/ cursos_indeci/documentos/CBSC-incidente.pdf

\section{CITAR ESTE ARTICULO:}

Soriano Torres, L. E., \& Robles Salguero, R. E. (2020). Evaluación social de las competencias de gestión de riesgos de un municipio en Ecuador. RECIMUNDO, 4(4), 411-433. https://doi.org/10.26820/recimundo/4.(4).octubre.2020.411-433 


\section{Anexos}

\section{INDICADORES POR GESTIÓN DE IMPACTO EN GESTIÓN DE RIESGOS (ANEXO IV)}

El análisis a las instituciones a nivel administrativo desde el nivel gubernamental nacional hasta el local revela la necesidad de una mejor la articulación de las instituciones integrantes del Sistema Nacional Descentralizado de Gestión de Riesgos-SNGR y la gestión de las Unidades de Gestión de Riesgos cantonales. Aunque ha existido un desarrollo positivo en la capacidad de los municipios en la gestión de los riesgos presentes en sus territorios, existe una necesidad adicional de integrar la identificación y análisis de riesgos y vulnerabilidades en la planificación municipal en el desarrollo y ordenamiento territorial. Esto permitirá el trabajo desde la reducción del riesgo de desastres en las acciones preventivas con las instituciones públicas, privadas y comunidad en general.

La planificación municipal en el desarrollo y ordenamiento del territorio se lo construye a mediano plazo, debido a que sus servicios se enfocan a los riesgos recurrentes, dejando fuera dentro de la planificación los eventos peligrosos que se pueden suscitar a futuro. Un estudio de amenazas, vulnerabilidades, exposición y de susceptibilidad puede generar una base para construir a futuro escenarios para una planificación a largo plazo.

A nivel cantonal los municipios lideran el SNDGR, dando relevancia a las articulaciones y gestionen que se realicen en el territorio con las instituciones $u$ organismos presentes en él, para construir acciones estructurales (mitigación) y no estructurales (prevención) y preparar a las instituciones u organismos de socorro y salud para que se brinde la respuesta en el menor tiempo posible ante el impacto de evento peligroso. Los municipios tienen la competencia de asesorar, monitorear, gestionar y ejecutar las acciones antes mencionadas para reducir o minimizar los efectos negativos de los desastres, buscando brindar la seguridad a la ciudadanía y un territorio sostenible con el desarrollo y ordenamiento del mismo. El gobierno nacional asigna a los municipios un presupuesto para la ejecución de las funciones según las políticas y normativas en la gestión del riesgo de desastres; de este último existen brechas a evaluar a futuro.

El mejor instrumento que se ha recomendado para guiar a los tomadores de decisiones de manera eficiente, es el sistema de indicadores, que genera información a nivel local y comunitario para gestionar los riesgos por amenazas naturales. El sistema mide el progreso en las acciones de reducción y los elementos claves de los riesgos presentes en el territorio. El uso integral del sistema de indicadores es prometedora y novedosa para este ámbito, cuando se lo aplica en varias comunidades con base al marco conceptual releva una particular forma de reunir varios aspectos relacionados con riesgos brindando una visión amplia de la situación en el territorio. Uno de los beneficios al aplicarlo es que se genera la concientización en los actores locales involucrados en las actividades de riesgo. Las percepciones para enfrentan a los riesgos dan resultado a responder muchas interrogantes que nos servirán para estructurar un FODA e implementar dichos resultados en las acciones dentro del territorio.

Para disminuir el riesgo de desastres y desarrollar las competencias (Art. 13) a nivel cantonal de prevención, mitigación y rehabilitación se debe implementar acciones que fortalezcan el desarrollo de las capacidades en la gestión del riesgo de desastres (Asamblea Nacional, 2014). Por lo cual es indispensable identificar indicadores que nos permitan visualizar las 
vulnerabilidades y mejorar la toma de decisiones considerando aspectos económicos, sociales, institucionales y técnicos.

Entre dichos indicadores podemos mencionar población pobre y/o susceptible, asentamientos inseguros, tipo de evento peligroso, entre otros. Lo cual se puede ver reflejado de la siguiente manera:

\begin{tabular}{|c|c|}
\hline Datos & Descripción \\
\hline Porcentaje de pobreza en la población & $\begin{array}{l}\text { La población de más bajos ingresos generalmente } \\
\text { son los más afectados. }\end{array}$ \\
\hline Porcentaje de asentamientos inseguros & $\begin{array}{l}\text { Áreas propensas a sufrir efectos por desastres, } \\
\text { que usualmente coinciden con zonas de mayor } \\
\text { riesgo de inundación, deslizamientos, entre otros. }\end{array}$ \\
\hline $\begin{array}{l}\text { Tasa de promedio anual de crecimiento de la } \\
\text { población en la zona urbana }\end{array}$ & $\begin{array}{l}\text { Crecimiento urbano de la población debido a la } \\
\text { migración, arribo de personas desplazadas, lo cual } \\
\text { trae problemas y dificultades. }\end{array}$ \\
\hline Número de desastres por tipo & $\begin{array}{l}\text { Sismo, inundación, deslizamientos, erupción } \\
\text { volcánica, entre otros. }\end{array}$ \\
\hline Número de afectados o damnificados & $\begin{array}{l}\text { Población, personas, familias, grupo etario, entre } \\
\text { otros. }\end{array}$ \\
\hline $\begin{array}{l}\text { Número de intervenciones exitosas en } \\
\text { Gestión del Riesgo de Desastres }\end{array}$ & $\begin{array}{l}\text { Casos de desastres con intervenciones en GR con } \\
\text { éxito. }\end{array}$ \\
\hline $\begin{array}{l}\text { Número de intervenciones no exitosas en } \\
\text { Gestión del Riesgo de Desastres }\end{array}$ & $\begin{array}{l}\text { Casos de desastres con intervenciones en GR no } \\
\text { exitoso. }\end{array}$ \\
\hline $\begin{array}{l}\text { Número de proyectos sociales en Gestión del } \\
\text { Riesgo de Desastres }\end{array}$ & $\begin{array}{l}\text { Casos en donde se ejecuten proyectos sociales en } \\
\text { gestión de riesgos para minimizar los riesgos. }\end{array}$ \\
\hline
\end{tabular}

Tabla II. Identificación de datos para determinar indicadores para las intervenciones de la GRD

Crear indicadores de impacto en donde se pueda visibilizar los resultados sobre las intervenciones de la Gestión del Riesgo de Desastres en casos de eventos peligrosos suscitados, para mejorar la toma de decisiones de las autoridades y concientizar a la población. 